\title{
AUTOMATED AND PERMANENT LONG-RANGE TERRESTRIAL LASER SCANNING IN A HIGH MOUNTAIN ENVIRONMENT: SETUP AND FIRST RESULTS
}

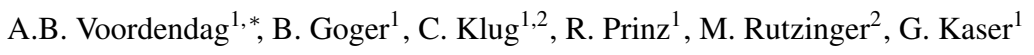 \\ ${ }^{1}$ Department of Atmospheric and Cryospheric Sciences (ACINN), University of Innsbruck, Austria - \\ (annelies.voordendag, brigitta.goger, christoph.klug, rainer.prinz, georg.kaser)@uibk.ac.at \\ ${ }^{2}$ Institute of Geography, University of Innsbruck, Austria - martin.rutzinger@uibk.ac.at
}

Commission II, WG II/10

KEY WORDS: topographic LiDAR, RIEGL VZ-6000, terrestrial laser scanning, cryosphere, change detection and time series analysis, uncertainty analysis

\begin{abstract}
:
A terrestrial laser scanner (TLS) of the type RIEGL VZ-6000 has been permanently installed and automated at Hintereisferner glacier located in the Ötztal Alps, Austria, to identify snow (re)distribution from surface height changes. A first case study is presented that shows and discusses detected snow distribution at the glacier after a snowfall event, together with concurrent snow erosion and deposition caused by avalanches. The paper shows the potential of a TLS system in a high mountain environment, which is also applicable to other environmental mapping applications. It introduces the setup of the TLS system, its automation procedure, and a first and preliminary uncertainty analysis. TLS data are generally influenced by four uncertainty sources: atmospheric conditions, scanning geometry, mechanical properties, and surface reflectance properties. The first three sources have significant influence on the TLS data at Hintereisferner, whereby the total accuracy of the TLS system is estimated to be in a range of a few decimetres, subject to ongoing more detailed data analysis.
\end{abstract}

\section{INTRODUCTION}

Terrestrial laser scanning (TLS) is an active sensing system that rapidly acquires high-resolution $3 \mathrm{D}$ point clouds of the Earth's surface by emitting and receiving a pulsed laser light. Recent developments made it possible to scan at long $(>2 \mathrm{~km})$ ranges. The number and variety of remote sensing applications of TLS instruments continues to increase, including engineering and environmental mapping applications. One result of this development is the RIEGL VZ-6000, a long range TLS introduced by Riegl Laser Measurement Systems, which is suitable for remote sensing of snow and ice due to the scanning wavelength of $1064 \mathrm{~nm}$ at distances up to $6 \mathrm{~km}$. The pioneer publication reporting the use of the RIEGL VZ-6000 for glaciological applications originates from measurements in 2013 on Haut Glacier d'Arolla in the Swiss Alps (Gabbud et al., 2015). This study investigated glacier surface ablation at seasonal and daily scales and shows that the scanner provides mean surface changes of $0.050 \pm 0.002 \mathrm{~m}^{3} \mathrm{~m}^{-2} \mathrm{~d}^{-1}$ at seasonal scale at ranges up to $3.7 \mathrm{~km}$. The paper laid a good groundwork for scanning glaciers at a long range but misses, unfortunately and despite obvious noise in the data, to provide an uncertainty assessment of the scanner.

Consequently, the application and validation to monitor glacier mass balance with the RIEGL VZ-6000 has been tested for various glaciers smaller than $0.5 \mathrm{~km}^{2}$ in the Swiss Alps (Fischer et al., 2016) and for Urumqi Glacier No. 1, eastern Tien Shan, China (Xu et al., 2019). These studies compared the geodetic results to direct glaciological mass balance measurements and showed comparable results for both methods. However, these studies were applied to small glaciers at seasonal time scales and with maximum ranges of approx. $2.5 \mathrm{~km}$ and again without an extensive uncertainty assessment. To our knowledge, there

\footnotetext{
* Corresponding author
}

has not yet been a study published concerning the quality control of TLSs on glaciers ranging longer than $2 \mathrm{~km}$ at daily or even hourly resolution.

Subsequently, the permanent installation of TLSs is worldwide rare. We are aware of installations of RIEGL VZ-2000 laser scanners at beaches to investigate coastal dynamics in the Netherlands (Vos et al., 2017; Anders et al., 2019) and in Belgium (Deruyter et al., 2020). This research is similar to laser scanning at glacierized environments, because sandy coast dynamics are comparable with snow cover dynamics as it occurs on high spatiotemporal scales (Comola and Lehning, 2017; Cowell et al., 2003). On the other hand, atmospheric conditions at shoreline regions are incomparable with conditions in high relief, mountainous terrain.

Other examples of automated and/or permanent TLSs include near-real-time change detection of the Séchilienne landslide in France (Kromer et al., 2017), a snow study site in the eastern Sierra Nevada to review TLS positional accuracies (Hartzell et al., 2015), a site in Finland to monitor structural and phenological dynamics of boreal forest canopy (Campos et al., 2021) and a study area in the Western Austrian Alps to monitor potential avalanche slopes in high-alpine terrain (Adams et al., 2014). The limitations of these studies are that the scanners were installed for shorter periods of time (weeks to seasons) at shorter ranges (Kromer et al., 2017; Campos et al., 2021; Adams et al., 2014) or a scanner operating at a wavelength unsuitable for snow and ice was used (Hartzell et al., 2015).

We introduce the automated and permanent long-range TLS system Im Hinteren Eis (Sect. 2) at a valley glacier in the Austrian Alps. Our aim is to clarify its automation process (Sect.2.1 and identify the uncertainty sources influencing the accuracy of the system (Sect. 3 and 4). In addition, a case study during a 
snowfall event is shown in Sect. 4.4 The results are discussed, combined with an outlook on the continued TLS quality assessment and the planned glaciological research (Sect. 5).

\section{TERRESTRIAL LASER SCANNER IM HINTEREN EIS: TECHNICAL SETUP}

A RIEGL VZ-6000 was installed close to Hintereisferner (HEF), a valley glacier located in the Rofental catchment in the Ötztal Alps, Austria, to identify snow (re)distribution from surface height changes. The glacier has a length of approx. $6.3 \mathrm{~km}$ ranging between the Weißkugel mountain peak (3739 $\mathrm{m}$ a.s.l.) and the glacier tongue at $2460 \mathrm{~m}$ a.s.l. (data from 2018). The glacier is part of the Open Air Laboratory Rofental (Strasser et al., 2018) and has been a key research site for glaciological studies since the early days of glacier research (Hess and Blümcke, 1899). Continuous long-term mass balance observations dating back to the year 1952/53 (Kuhn et al., 1999), as well as velocity and ice thickness change measurements since 1894 (Span et al., 1997) are available. The glacier is classified as one of the key 'reference glaciers' by the World Glacier Monitoring Service ${ }^{1}$

The installation of the RIEGL VZ-6000 at HEF was planned in 2014/15 and finally installed in September 2016 (Fig. 1). The scanner is located on the Austrian-Italian border at an altitude of $3250 \mathrm{~m}$ a.s.1.. The container in which the scanner is installed was too heavy to be carried by a helicopter and thus a temporary road was made to the mountain ridge and covered again after installation was done. The final position of the container is close to the mountain top Im Hinteren Eis (IHE, Fig. 2, blue dot in Fig. 5). The container is equipped with a desktop PC enabling remote access and control over the scanner. The container has windows that have to be opened before scanning and the scanner is protected with a robust industrial protective housing, which is a hermetically-sealed cover with thermo-electric coolers and forced-air cooling to stabilize temperature conditions in the harsh environment. The power supply to the container is achieved via a power line from the nearby ski resort Alpin Arena Schnals/Senales (South Tyrol, Italy).

The Digital Elevation Model (DEM) at one-metre-resolution retrieved from the point cloud data covers an area of $62.8 \%$ of the glacier in comparison to the glacier outlines of the airborne laser scanning (ALS) data acquisition from 2017. These gaps in glacier coverage are mainly related to concave areas in the accumulation zone of the glacier, partially at elevations higher than the TLS position. In that sense, an installation of the system at a higher altitude would have been more advantageous, but this was not possible due to the local topography and power supply. The maximum field of view (FOV) is $360^{\circ}$ in the horizontal and $60^{\circ}\left(-30^{\circ} /+30^{\circ}\right)$ in the vertical direction (RIEGL, 2019a). A scan covering HEF has $157^{\circ}$ and $40^{\circ}$ FOV in horizontal and vertical direction, respectively. A pulse repetition rate (PRR) of $30 \mathrm{kHz}$ and an angular step width of $0.01^{\circ} \mathrm{im}-$ plies a scanning time of approx. $45 \mathrm{~min}$ and results in roughly 43 million points.

Besides the scanner being the core instrument of this study, an eddy-covariance (EC) flux tower (Aubinet et al., 2012, Stiperski and Rotach, 2015) is located close to the TLS container to observe standard meteorological quantities as well as turbulent fluxes and turbulence kinetic energy (TKE). Two automatic webcams were installed on the TLS container ${ }^{2}$, deliver-

\footnotetext{
1 https://wgms.ch/products_ref_glaciers/

2 https://www.foto-webcam.eu/webcam/hintereisferner1/
}

ing photos of the glacier every thirty minutes (Fig. 3). Furthermore, on the opposite slope the automatic weather station Station Hintereis (red dot in Fig. 5) observes meteorological variables such as temperature, relative humidity, wind speed, precipitation, and radiation.

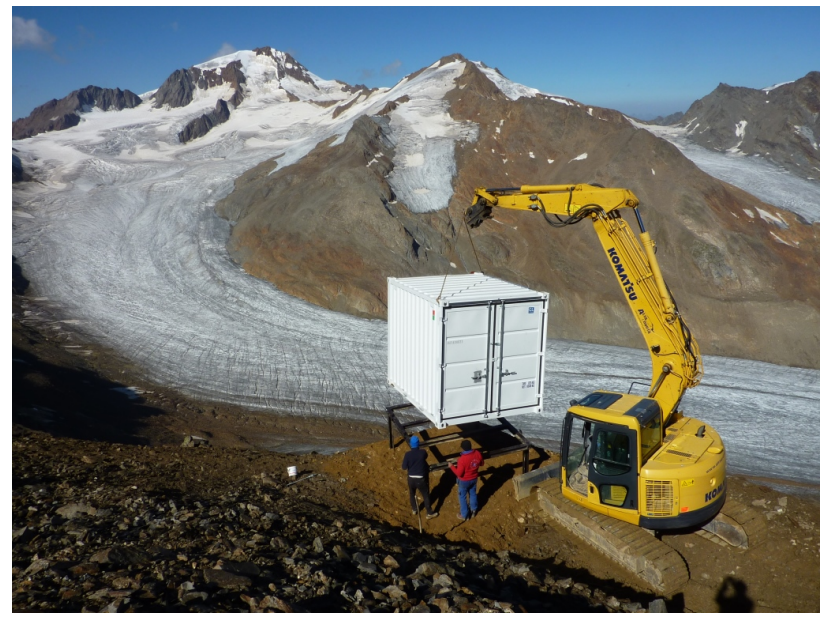

Figure 1. Installation of the TLS container in September 2016. The snow covered mountain top on the left side is Weißkugel (3739 m a.s.1.). Photo: Daniela Brugger, 13 September 2016.

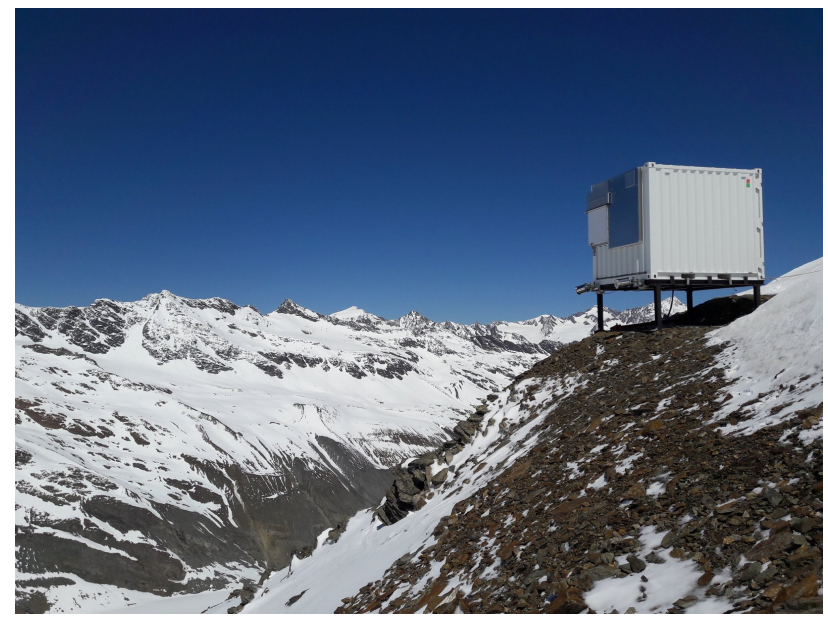

Figure 2. The final position of the TLS container Im Hinteren Eis, looking in northern direction.

Photo: Annelies Voordendag, 7 May 2020.

\subsection{Permanent and automated laser scanning}

The advantage of the TLS system IHE is its permanent installation and its fully automated scanning process. The position of the device is fixed and this enables an easier co-registration of scans. From October 2016 occasional scans were taken. From March 2019, the TLS system IHE has been in operational use, as since then remote access was possible. Scans were manually initiated every day if scan conditions, power supply, and remote access allowed to make a scan and personnel was available. Since June 2020, the process is fully automated and consists of roughly ten steps, as described in the following section and Fig. 4

First of all, the desktop PC in the container controls the protective housing of the scanner and the windows of the container. In step 1, the windows are opened and simultaneously, the connection between the protective housing and the scanner is established. Before the scan starts, five scanning parameters need 


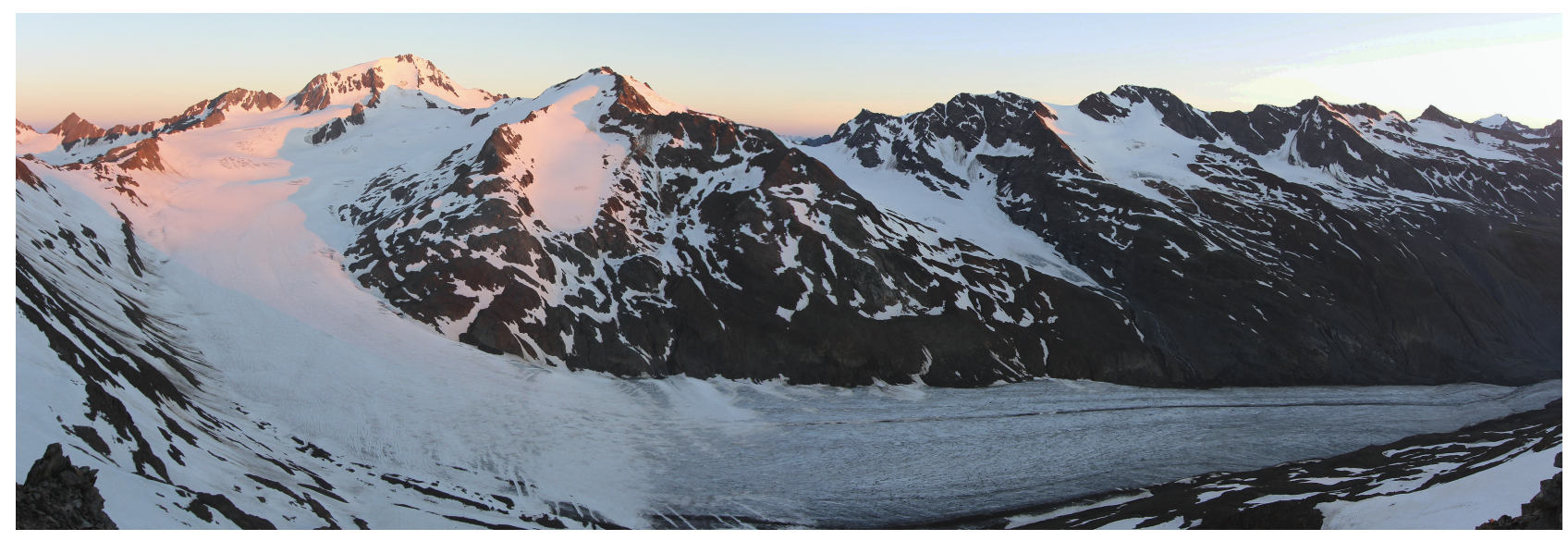

Figure 3. Merged webcam photos from 30 June 2018, 05:30 AM. Copyright: www.foto-webcam.eu

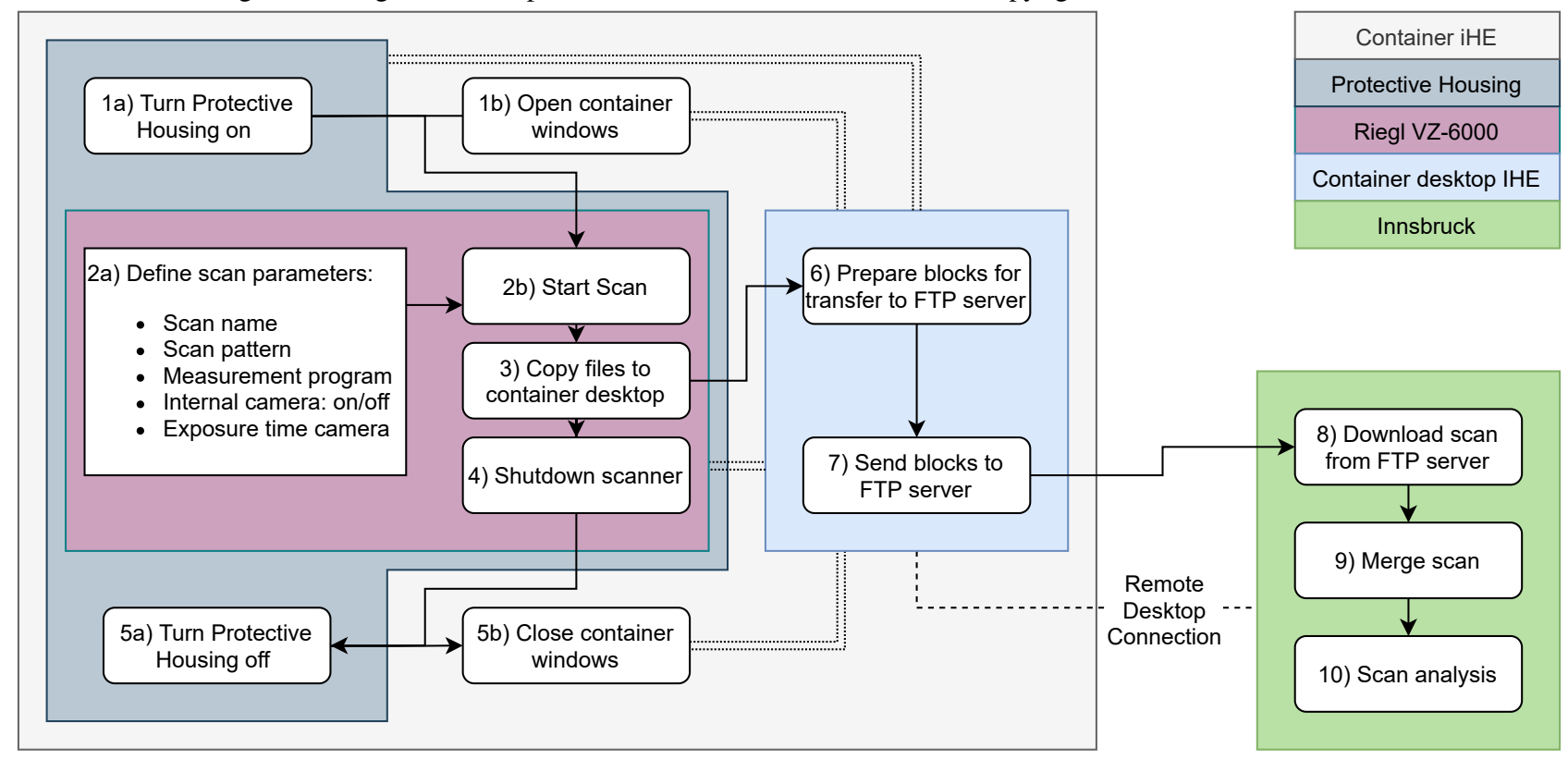

Figure 4. Flowchart of the automated scanning process at IHE

to be defined in step 2a. All scans are saved under the same project name, but at IHE, for every new scan a new scan position is defined. The scan pattern depends on whether a complete glacier or detail scan was made. The measurement program is the PRR and can be set to $30,50,150$ and $300 \mathrm{kHz}$. The RIEGL VZ-6000 also has a built-in digital camera. Images are automatically taken if the scan acquisition is in daylight time with an appropriate camera exposure time, to ensure that images are not over- or underexposed. After these parameters are defined, the scan starts (step 2b). The scan data is saved locally on the scanner. After a scan is completed, the data is copied to the desktop in the container at IHE (step 3) and the scanner is shutdown (step 4). In step 5, the connection between protective housing and scanner is turned off and the windows of the container are closed again. In order to guarantee a zero-loss data transmission under sometimes unstable connections between IHE and the FTP data server, it is decided to cut the scan data and the corresponding images in blocks of $15 \mathrm{MB}$ (step 6). If the connection breaks down, it is not needed to repeat the entire upload of the scan to the FTP server, but single blocks can be uploaded again. The upload of a scan to the FTP server (step 7) depends on the size of a scan, but generally, for a complete scan of the glacier (angular step width: $0.01^{\circ}$; PRR: $30 \mathrm{kHz}$ ) without images, it takes roughly 3 hours. After uploading, the scan is downloaded from the FTP server to a local computer in Innsbruck (step 8) and merged again (step 9). The scan is visually checked on artefacts (e.g. due to disturbance by unfavourable atmospheric conditions such as clouds, fog, or precipitation) before archived on a local server. The processing and analysis of the scan data can be started subsequently (step 10). The post-processing of the raw data is done using SAGA-LIS, which includes direct georeferencing, data registration, compression and filtering. The TLS data from the scan position are transformed from the scanner's own coordinate system (SOCS) into a global coordinate system (GLCS). The location of each scan is fixed in the GLCS after direct georeferencing. However as the orientation of each scan is continually adjusted to compute the best fit, the attitude angles of each scan campaign are different. Multi-temporal registration, also called relative registration, set the processed layer of an ALS campaign in September 2013 as a reference, where stable areas in the study area are used for quality control.

This workflow mostly runs smoothly, besides occasional power problems caused by lightning strikes in summer. In December 2020 the mechanical container windows broke down but, thanks to the protective housing, data acquisition was still possible. 


\section{METHODOLOGY}

The TLS system IHE provides an excellent setting not only for glacier monitoring and detailed data collection, but also to test the data quality of a long-range permanent TLS system. It is known that four major factors influence the quality of scanning data (Soudarissanane, 2016, Friedli et al., 2019), namely 1) atmospheric conditions, 2) scanning geometry, 3) mechanical properties, and 4) surface reflectance properties. All four factors appear in their respective orders of magnitude at HEF. After the scanning process had been automated, tests on atmospheric conditions, scanning geometry and mechanical properties were performed, as well as a case study after snowfall.

1. The accuracy of the scanner is strongly influenced by atmospheric conditions, having impact on the refraction and time of flight of the laser beam and the stability of the device. The range between laser source and target is not directly measured, but derived from the time of flight between the emitted and received pulse. The time of flight is depended on the group velocity in the air at the laser wavelength, which changes on changing air temperature, water vapour pressure and air pressure (RIEGL, 2019b). According to the manufacturer (RIEGL, 2019b), a change in temperature of $1{ }^{\circ} \mathrm{C}$ yields a change in correction of +1 parts per million (ppm) and a change in air pressure of $10 \mathrm{hPa}$ yields a change in correction of $-2.7 \mathrm{ppm}$. This atmospheric correction in ppm is used as scaling factor and a change of $50 \mathrm{ppm}$ results in a change of the measured range of $50 \mathrm{~mm}$ at a target range of $1000 \mathrm{~m}$. Pressure differences from the accumulation zone to the tongue of HEF roughly differ $100 \mathrm{hPa}$ and the temperature differences are in the range of several degrees, so the atmosphere influences the time of flight of the measurement.

Second, the atmospheric refraction of the laser beam is changed, leading to differences in the pulse lengths (Flach, 2000, Böckem et al., 2000, Soudarissanane, 2016, Friedli et al., 2019, Hejbudzka et al., 2012, Reiterer, 2012). The main atmospheric factors to take into account are the air temperature field, water vapour pressure, air turbulence, ambient light, and the optical depth of the atmosphere. The magnitude of the atmospheric effects was tested by making hourly scans during 26 hours (5 and 6 November 2020) in low-wind conditions. The differences between those scans are assumed to originate from changes in the atmospheric conditions, as no snow redistribution could be expected.

Last, the atmosphere influences the stability of the TLS, as the container with the device might experience vibrations induced by strong winds or air turbulence. As this can be tested with the inclination sensors of the device, this is elaborated further in Sect.4.3.

2. The influence of the scanning geometry is related to the incidence angle and the footprint diameter of the laser beam on the surface. The smaller the incidence angle and footprint, the more accurate the point in the point cloud. The beam divergence $\beta$ of the RIEGL VZ-6000 is $0.12 \mathrm{mrad}$ (RIEGL, 2019a). This means that the diameter of a laser spot perpendicular to the glacier surface at $2 \mathrm{~km}$ range is $24 \mathrm{~cm}$ and increases $12 \mathrm{~cm}$ for every kilometre further away from the scanner. The incidence angle $\alpha$ to the surface has been calculated with the terrain normal $n$ and the laser beam direction $l$ (Schaer et al., 2012) in Eq. 1

$$
\alpha=\arccos \left(\frac{l \cdot n}{|l||n|}\right)
$$

The footprint at the glacier surface is elliptical and the major axis $M$ of this theoretical footprint has been calculated (Sheng, 2008) with this incidence angle, the beam divergence and the range $R$ from the TLS to the point of interest in Eq. 2 under the assumption that the surface surrounding the point of interest is planar.

$$
M=2 R \cos \alpha \cdot \frac{\sin \beta}{\cos 2 \alpha+\cos \beta}
$$

3. Mechanical properties involve the positional uncertainty of the scanning mechanism and specifically the inclination of the scanner. Preliminary scans showed a radial pattern of stripes from the scanner position to the glacier. To investigate the cause of these stripes, the results of the internal inclinations sensors of the RIEGL VZ-6000 were examined. The minimal angular step width of the scanner is $0.002^{\circ}$, but the accuracy of the internal inclination sensors in the device are $\pm 0.008^{\circ}$ (RIEGL, 2019a). A deviation of $0.008^{\circ}$ indicates a vertical deviation of $18 \mathrm{~cm}$ at a range of $2 \mathrm{~km}$ from IHE.

4. Surface reflectance properties include the characteristics of the scanned surface. The area of interest contains three main surface types: snow, ice, and rocks. According to the manufacturer, the RIEGL VZ-6000 is especially applicable to snow and ice, because the reflectance of snow and ice is strong at the used wavelength of $1064 \mathrm{~nm}$ (Deems et al., 2013). The different surfaces mainly have implications on the received intensity and make it possible to distinguish between the three surface types. It is also possible to determine the glacier snow line and the snow cover extent, but the snow density cannot be derived from the intensity data (Prantl et al., 2017). We do not consider the surface reflectance properties further, as we do not specifically investigate intensity data and we assume the influence of the reflectance properties on the accuracy of the surface geometry to be negligible (Höfle et al., 2007).

As the uncertainty sources are well elaborated, we present data from the TLS system showing glacier surface changes after a snowfall event of approx. $1.5 \mathrm{~m}$ of fresh snow in December 2020 .

\section{RESULTS}

\subsection{Atmospheric conditions}

The comparison of hourly scans during 26 hours in wind still conditions showed significant differences from scan to scan (Fig. 5). After one particular two-hour period data showed a positive difference of roughly $10 \mathrm{~cm}$ in the accumulation zone and negative values of about $3 \mathrm{~cm}$ at the glacier tongue. Even more negative values occurred at the area around Station Hintereis and the TLS observations suggest a surface increase at the slope south of the glacier, although these artefacts are likely caused by quickly changing atmospheric conditions. After sunrise, local turbulence increases due to the heating of the slopes. To reduce this effect, the daily scans at HEF are taken during 
nighttime. There is less influence of ambient light, furthermore, the ambient atmosphere is assumed to have a stable stratification with limited turbulence, according to the observations from the EC station at IHE. The scans taken during the nighttime do not show the apparent local changes as mentioned above. We estimate the uncertainty caused by the atmosphere of the daily nighttime scans in the centimetre range.

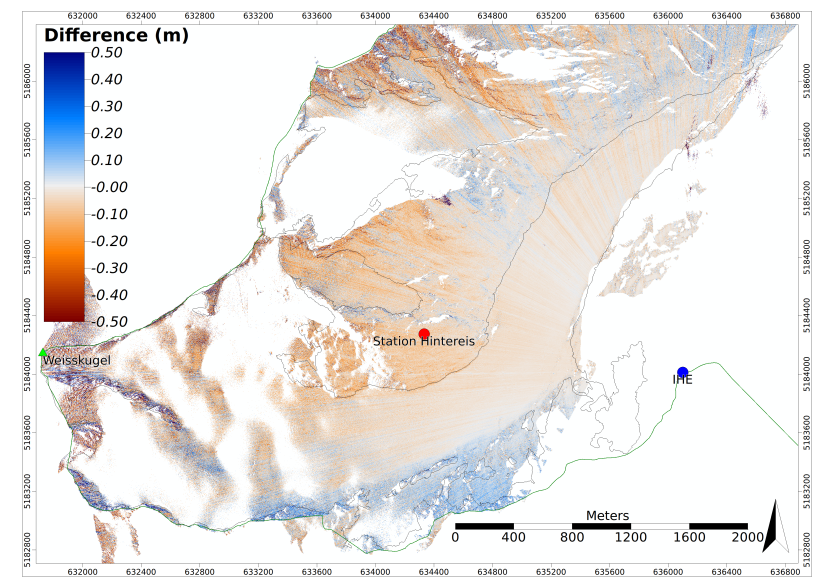

Figure 5. Difference plot of the scans made at 6 November 2020 between 12:11 and 14:06. The differences are given in $\mathrm{m}$. The permanent TLS IHE (blue dot), Station Hintereis (red dot), the mountain top Weißkugel (lime green triangle), the

Austrian-Italian border (green) and the borders of HEF according to ALS data of 2017 (black) are also given.

\subsection{Scanning geometry}

The incidence angles of the laser beam from IHE to every grid cell are calculated (Fig. 6) and are far from perpendicular. The order of magnitude of incidence angles is approx. $70-85^{\circ}$ at the glacier tongue and $60-70^{\circ}$ in the direction of Weißkugel. The most favorable incidence angles are found in the direction of Station Hintereis. Due to the oblique incidence angles at the study area, the footprint of the laser is elliptical and the major axis of this footprint also increases (Fig. 7). The minimal footprint (major axis ellipse) at the glacier is found between the direct line between IHE and Station Hintereis and is about $15 \mathrm{~cm}$, but rapidly increases to metre-range in the accumulation zone. These footprints are larger than the grid cell size of one metre and lead to large positional uncertainties in far range. The distribution of the footprint is assumed to be Gaussian (Schaer et al., 2012) and thus $1 \sigma$ is approx. $1 / 3$ of the largest extent of the footprint. The uncertainty caused by these large footprints are not yet quantified, but is expected to be in the order of decimetres and strongly depends on the distance from the scanner to the surface.

\subsection{Mechanical properties}

Fig. 5 shows the radial stripes probably induced by inaccuracies in the inclination sensors of the scanner. The inclination measurements are $1 \mathrm{~Hz}$, but approx. 5.6 scan lines are scanned per second at a PRR of $30 \mathrm{kHz}$ and a vertical FOV of $40^{\circ}$. This means that the inclination from scan line to scan line has been interpolated in the device. The inclination values of the scans made at 6 November 2020 are shown in Fig. 8 If the TLS would have scanned $360^{\circ}$ (horizontal FOV), the data show a sine wave, as plotted with a least squares method in Fig. 8 This is caused by the slightly tilted installation of the scanner

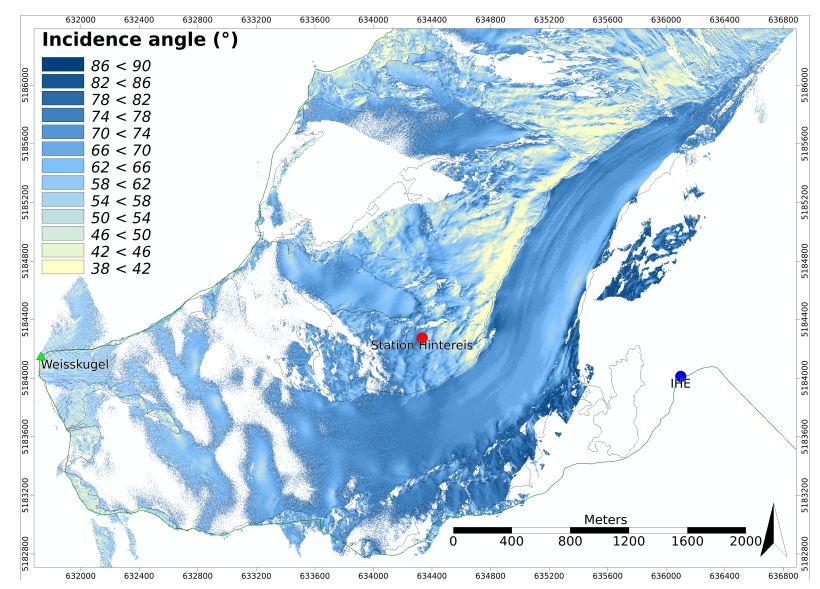

Figure 6. The incidence angles of the laser beam from the position of IHE in ${ }^{\circ}$ from the zenith as calculated with the scan of 6 November 2020 14:06.

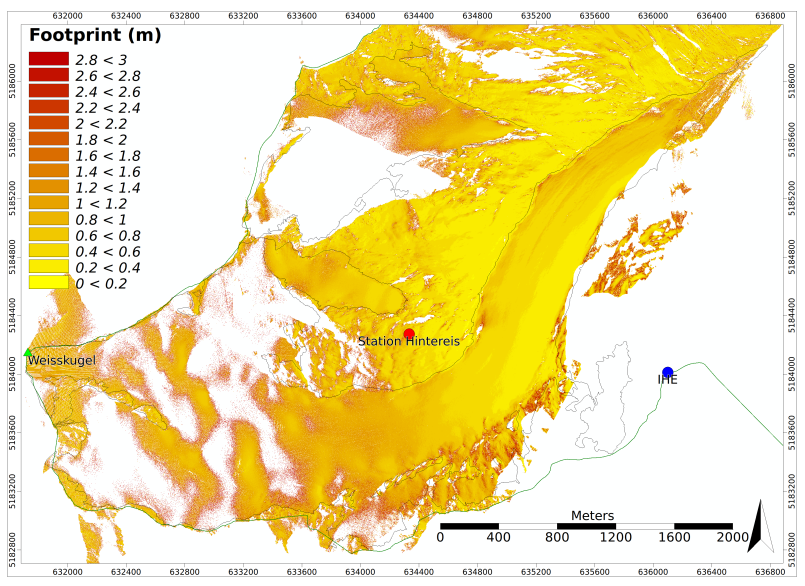

Figure 7. The major axis of the elliptical footprint of the laser beam from the position of IHE in metres. Scan of 6 November 2020 14:06.

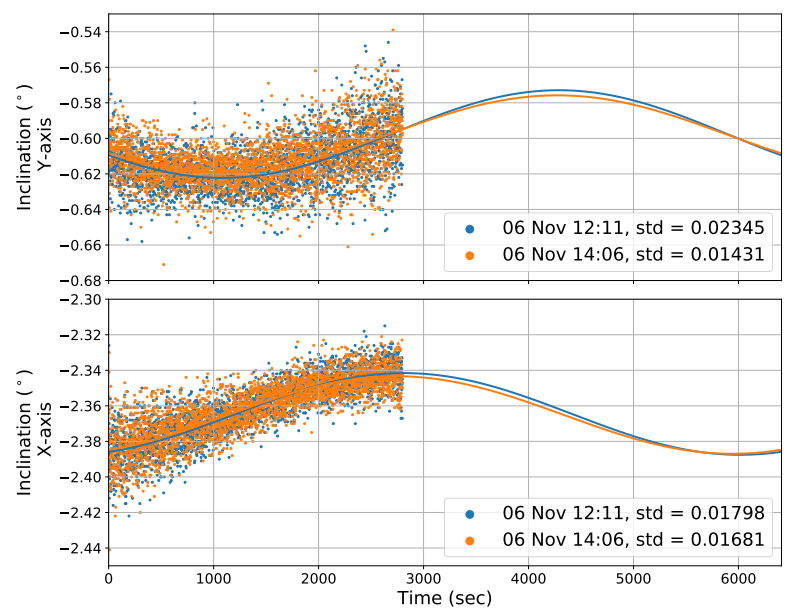

Figure 8. Inclination measurements of two scans taken at 6 November 2020 and the standard deviation of the data.

to ensure a direction of view down to the glacier. Furthermore, the inclination values show noise larger than the accuracy of the inclination sensors $\left( \pm 0.008^{\circ}\right)$. The standard deviation of the different inclination data sets also differs from scan to scan (See values in the legend of Fig. 8) and increases with increas- 


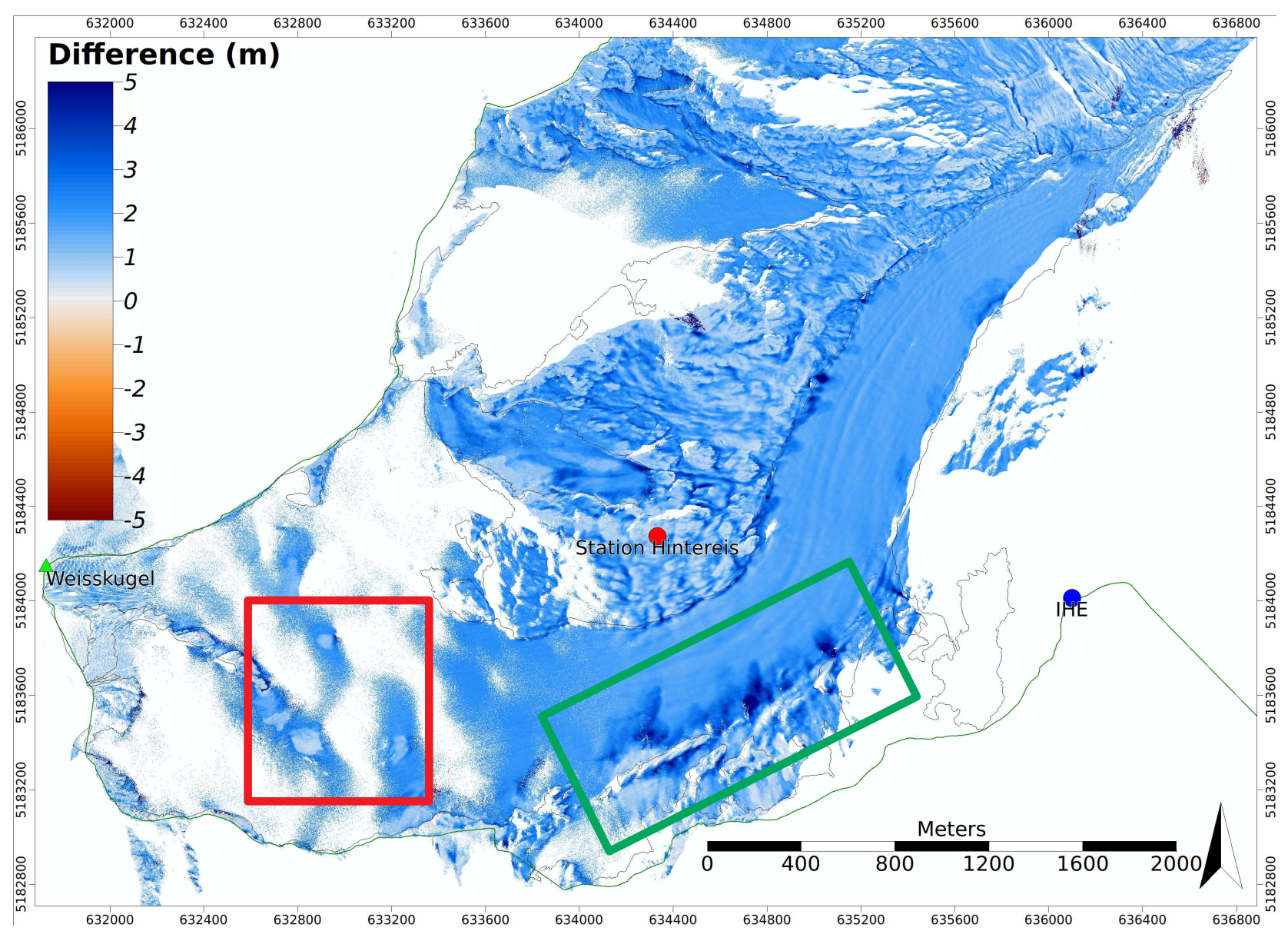

Figure 9. Difference plot between 1 and 10 December 2020. Snow erosion (red) and snow deposition (green) caused by avalanches has been marked with boxes.

ing TKE values, possibly indicating vibrations of the scanner in turbulent air conditions. No significant relationship between inclination values and strong wind conditions has been found. Last, the stability of the container has been investigated. The mean roll and pitch value for every scan since 2016 has been calculated, but no movement in a distinct direction has been identified. On the other hand, the inclination sensors show deviations depending on the season, which might be caused by cooling and warming of the container. More research, for example with an Inertial Measurement Unit (IMU) mounted on the container, is needed to prove this hypothesis. The combination of the interpolation of the inclination data and the noise at the signal causes outliers in the data, which become more apparent if elevation differences between two time steps are calculated. We computed the outliers of single points to be in a decimetre range, but this averages out as soon as grids are calculated. Therefore, the radial pattern is more visible further away from the scanner, as less points per grid cell are measured and thus an outlier has bigger influence on the final grid height calculation. We estimate the final uncertainty assigned to the given mechanical properties at a one-metre-resolution grid to be approx. $10 \mathrm{~cm}$.

\subsection{Case study: snowfall December 2020}

The TLS system is able to capture differences before and after snowfall events bigger than the uncertainty of the device. Fig. 9 shows the grid differences between 1 and 10 December 2020, suggesting an increase in snow depth of approx. $1.5 \mathrm{~m}$ on the glacier. This is in correspondence with snow depth measurements on 17th of December and an observed precipitation of $166 \mathrm{~mm}$ at the precipitation gauge at IHE. Avalanches are also observed, as they erode and deposit several meters of snow (boxes in Fig. 9].

\section{CONCLUDING REMARKS}

Glacier surface changes caused by snowfall and snow redistribution by wind play a pivotal role in glacier mass balance studies (Mott et al., 2008, Dadic et al., 2010). Other studies have already shown the possibility to capture the yearly and seasonal glacier mass balance with TLSs (Gabbud et al., 2015, Fischer et al., 2016, Xu et al., 2019), but so far it has not been possible to distinguish glacier mass balance at higher temporal resolution. If more knowledge is gained about the snow redistribution, our knowledge about the distributed surface mass balance (Cogley et al., 2011) improves.

This study presents the setup and configuration of the permanent long-range laser scanning system at Hintereisferner. The three main sources (atmospheric conditions, scanning geometry and mechanical properties) influencing the data quality have already been studied in other environmental settings (Fey and Wichmann, 2016, Hartzell et al., 2015. Friedli et al., 2019. Hejbudzka et al., 2012), but not yet been quantified at ranges $>2 \mathrm{~km}$ at high spatiotemporal resolution. Despite these inaccuracies, the TLS IHE is already able to capture surface changes after snowfall events bigger than the uncertainty of the 
device (Fig. 9) and we expect that it is possible to capture higher resolution processes, such as snow redistribution on the glacier, after a detailed quality assessment of the TLS data at HEF.

At this point, the accuracy of the total system is estimate in the lower decimetre-range and ongoing analysis aims for a detailed quantification of the atmospheric conditions and mechanical properties. The scanning geometry will be further investigated with the decomposition of the major axis of the footprint in $\mathrm{x}-, \mathrm{y}-$ and $\mathrm{z}$-components to get the standard deviation in these directions. Generally, the main source causing uncertainty in an automated and permanent long-range TLS system depends on the setup of the system, and all mentioned uncertainties increase by increasing scanning distances. Concluding, the installation of the RIEGL VZ-6000 at HEF with scanning distances up to $4.6 \mathrm{~km}$ and an estimated accuracy in the decimetre-range is an one-of-a-kind setup, which not only enables to acquire the geodetic glacier mass balance of HEF, it also promises high potential for snow cover change studies and other environmental sciences. Second, the data acquired by the system extends the data set with over 150 years of hydro-meteorological and glaciological observations of the Open Air Laboratory Rofental (Strasser et al., 2018).

\section{ACKNOWLEDGEMENTS}

This research is embedded in the SCHISM project (Snow Cover dynamics and HIgh reSolution Modelling) and is funded by the Austrian Science Fund (FWF) and the German Research Foundation (DFG) research project I3841-N32 Snow Cover Dynamics and Mass Balance on Mountain Glaciers.

\section{REFERENCES}

Adams, M. S., Bauer, A., Paar, G., 2014. Monitoring snow avalanche terrain with automated terrestrial laser scanning. 2014 IEEE Geoscience and Remote Sensing Symposium, IEEE.

Anders, K., Lindenbergh, R. C., Vos, S. E., Mara, H., de Vries, S., Höfle, B., 2019. High-Frequency 3D Geomorphic Observation Using Hourly Terrestrial Laser Scanning Data Of A Sandy Beach. ISPRS Annals of Photogrammetry, Remote Sensing and Spatial Information Sciences, IV-2/W5, 317-324.

Aubinet, M., Vesala, T., Papale, D. (eds), 2012. Eddy Covariance. Springer Netherlands.

Böckem, B., Flach, P., Weiss, A., Hennes, M., 2000. Refraction influence analysis and investigations on automated elimination of refraction effects on geodetic measurements. Paper to XVI IMEKO World Congress, 25-28.

Campos, M. B., Litkey, P., Wang, Y., Chen, Y., Hyyti, H., Hyyppä, J., Puttonen, E., 2021. A Long-Term Terrestrial Laser Scanning Measurement Station to Continuously Monitor Structural and Phenological Dynamics of Boreal Forest Canopy. Frontiers in Plant Science, 11, 2132. https://www.frontiersin.org/article/10.3389/fpls.2020.606752.

Cogley, J. G., Hock, R., Rasmussen, L., Arendt, A., Bauder, A., Braithwaite, R., Jansson, P., Kaser, G., Möller, M., Nicholson, L., Zemp, M., 2011. Glossary of glacier mass balance and related terms. IHP-VII technical documents in hydrology, 86.

Comola, F., Lehning, M., 2017. Energy- and momentumconserving model of splash entrainment in sand and snow saltation. Geophysical Research Letters, 44(3), 1601-1609.
Cowell, P. J., Stive, M. J., Niedoroda, A. W., de Vriend, H. J., Swift, D. J., Kaminsky, G. M., Capobianco, M., 2003. The coastal-tract (part 1): a conceptual approach to aggregated modeling of low-order coastal change. Journal of Coastal Research, 812-827.

Dadic, R., Mott, R., Lehning, M., Burlando, P., 2010. Wind influence on snow depth distribution and accumulation over glaciers. Journal of Geophysical Research, 115(F1).

Deems, J. S., Painter, T. H., Finnegan, D. C., 2013. Lidar measurement of snow depth: a review. Journal of Glaciology, 59(215), 467-479.

Deruyter, G., De Sloover, L., Verbeurgt, J., De Wulf, A., Vos, S., 2020. Macrotidal beach monitoring (Belgium) using hypertemporal terrestrial lidar. FIG Working Week 2020 : Smart surveyors for land and water management, Proceedings, 13.

Fey, C., Wichmann, V., 2016. Long-range terrestrial laser scanning for geomorphological change detection in alpine terrain - handling uncertainties. Earth Surface Processes and Landforms, 42(5), 789-802.

Fischer, M., Huss, M., Kummert, M., Hoelzle, M., 2016. Application and validation of long-range terrestrial laser scanning to monitor the mass balance of very small glaciers in the Swiss Alps. The Cryosphere, 10(3), 1279-1295.

Flach, P., 2000. Analysis of refraction influences in geodesy using image processing and turbulence models. PhD thesis, ETH Zurich.

Friedli, E., Presl, R., Wieser, A., 2019. Influence of atmospheric refraction on terrestrial laser scanning at long range. Proceedings of the 4th Joint International Symposium on Deformation Monitoring (JISDM), 15-17 May 2019.

Gabbud, C., Micheletti, N., Lane, S. N., 2015. Lidar measurement of surface melt for a temperate Alpine glacier at the seasonal and hourly scales. Journal of Glaciology, 61(229), 963974.

Hartzell, P. J., Gadomski, P. J., Glennie, C. L., Finnegan, D. C., Deems, J. S., 2015. Rigorous error propagation for terrestrial laser scanning with application to snow volume uncertainty. Journal of Glaciology, 61(230), 1147-1158.

Hejbudzka, K., Lindenbergh, R., Soudarissanane, S., C, A., 2012. Influence of atmospheric conditions on the range distance and number of returned points in Leica Scanstation 2 point clouds. International Archives of the Photogrammetry, Remote Sensing and Spatial Information Sciences - ISPRS Archives, 38.

Hess, H., Blümcke, A., 1899. Untersuchungen am Hintereisferner. Wissenschaftliche Ergänzungshefte zur "Zeitschrift des deutschen und österreichischen Alpenvereins, der deutsche und österreichische Alpenverein.

Höfle, B., Geist, T., Rutzinger, M., Pfeifer, N., 2007. Glacier surface segmentation using airborne laser scanning point cloud and intensity data. International Archives of Photogrammetry, Remote Sensing and Spatial Information Sciences, 36(Part 3), W52.

Kromer, R. A., Abellán, A., Hutchinson, D. J., Lato, M., Chanut, M.-A., Dubois, L., Jaboyedoff, M., 2017. Automated terrestrial laser scanning with near-real-time change detection monitoring of the Séchilienne landslide. Earth Surface Dynamics, 5(2), 293-310. 
Kuhn, M., Dreiseitl, E., Hofinger, S., Markl, G., Span, N., Kaser, G., 1999. Measurements and Models of the Mass Balance of Hintereisferner. Geografiska Annaler, Series A: Physical Geography, 81(4), 659-670.

Mott, R., Faure, F., Lehning, M., Löwe, H., Hynek, B., Michlmayer, G., Prokop, A., Schöner, W., 2008. Simulation of seasonal snow-cover distribution for glacierized sites on Sonnblick, Austria, with the Alpine3D model. Annals of Glaciology, 49, 155-160.

Prantl, H., Nicholson, L., Sailer, R., Hanzer, F., Juen, I., Rastner, P., 2017. Glacier Snowline Determination from Terrestrial Laser Scanning Intensity Data. Geosciences, 7(3), 60.

Reiterer, A., 2012. Modeling Atmospheric Refraction Influences by Optical Turbulences Using an Image-Assisted Total Station. zfv-Zeitschrift für Geodäsie, Geoinformation und Landmanagement, 137(3).

RIEGL, 2019a. Datasheet RIEGL VZ-6000. RIEGL Laser Measurement Systems, Horn, Austria.

RIEGL, 2019b. RiSCAN PRO. 2.8.0 edn, RIEGL Laser Measurement Systems, Horn, Austria.

Schaer, P., Skaloud, J., Landtwing, S., Legat, K., 2012. Accuracy Estimation for Laser Point Cloud Including Scanning Geometry. International Archives of Photogrammetry, Remote Sensing and Spatial Information Sciences, 36.

Sheng, Y., 2008. Quantifying the Size of a Lidar Footprint: A Set of Generalized Equations. IEEE Geoscience and Remote Sensing Letters, 5(3), 419-422.

Soudarissanane, S., 2016. The geometry of terrestrial laser scanning; identification of errors, modeling and mitigation of scanning geometry. PhD thesis, Delft University of Technology.

Span, N., Kuhn, M. H., Schneider, H., 1997. 100 years of ice dynamics of Hintereisferner, Central Alps, Austria, 1894-1994. Annals of Glaciology, 24, 297-302.

Stiperski, I., Rotach, M. W., 2015. On the Measurement of Turbulence Over Complex Mountainous Terrain. Boundary-Layer Meteorology, 159(1), 97-121.

Strasser, U., Marke, T., Braun, L., Escher-Vetter, H., Juen, I., Kuhn, M., Maussion, F., Mayer, C., Nicholson, L., Niedertscheider, K., Sailer, R., Stötter, J., Weber, M., Kaser, G., 2018. The Rofental: a high Alpine research basin (1890-3770 $\mathrm{m}$ a.s.1.) in the Ötztal Alps (Austria) with over 150 years of hydrometeorological and glaciological observations. Earth System Science Data, 10(1), 151-171.

Vos, S., Lindenbergh, R., de Vries, S., 2017. Coastscan : Continuous monitoring of coastal change using terrestrial laser scanning. Coastal Dynamics 2017, Paper No. 233.

Xu, C., Li, Z., Li, H., Wang, F., Zhou, P., 2019. Long-range terrestrial laser scanning measurements of annual and intra-annual mass balances for Urumqi Glacier No. 1, eastern Tien Shan, China. The Cryosphere, 13(9), 2361-2383. 